\section{Reativação de garimpo de ouro no Granito Novo Mundo (PAAF) após realização de IP.}

Alexandre Santos Jeronimo da Costa*, Eduardo Xavier Seimetz, Rafael Espindola Canata, Willian Giovanni Zan e Vicente de Paula Pinto

\section{Copyright 2019, SBGf - Sociedade Brasileira de Geofísica}

This paper was prepared for presentation during the $16^{\text {th }}$ International Congress of the Brazilian Geophysical Society held in Rio de Janeiro, Brazil, 19-22 August 2019.

Contents of this paper were reviewed by the Technical Committee of the $16^{\text {th }}$ International Congress of the Brazilian Geophysical Society and do not necessarily represent any position of the SBGf, its officers or members. Electronic reproduction or storage of any part of this paper for commercial purposes without the written consent of the Brazilian Geophysical Society is prohibited.

\section{Resumo}

A região garimpeira de Novo Mundo situa-se na porção Leste da Província Aurífera Alta Floresta (PAAF), Norte do Mato Grosso. Nessa região, as mineralizações auríferas ocorrem ao longo de zonas de cisalhamento com percolação de fluídos enriquecidos em sílica, enxofre e metais, bem como o ouro. $\mathrm{Na}$ aquisição de dados de geofísica terrestre usaram-se os métodos da eletrorresistividade e da polarização induzida. As aquisições geofísicas ocorreram nas proximidades do Garimpo da Raimunda, visto a existência de uma cava desativada. No local previsto para a ocorrência da mineralização aurífera identificaram-se valores de cargabilidade superior a $42 \mathrm{mV}$ / $\checkmark$ e de resistividade menor que 100 ohm.m.

\section{Introdução}

A atividade garimpeira no centro norte de Mato Grosso (MT), Brasil, eve início com a abertura da rodovia BR163 que interliga Cuiabá (MT) a Santarém (PA). Nessa região, as primeiras ocorrências auríferas aconteceram no rio Peixoto de Azevedo, em 1978, e o ápice da produção foi alcançado 11 anos depois. Segundo Paes de Barros (2007) entre 1980 e 1999 a produção de ouro nos limites da
Província Aurífera de Alta Floresta (PAAF) foi da ordem de 160 toneladas.

O método de polarização induzida (IP) é comumente aplicado na exploração mineral em fases avançadas da pesquisa, sobretudo na prospecção de zonas auríferas associadas a sulfetos disseminados. Usa-se a geofísica na exploração mineral desde que existam variações em propriedades físicas associadamente ao alvo da exploração que sejam passíveis de se enquadrarem na definição anteriormente apresentada.

Este trabalho tem o objetivo de verificar a aplicabilidade de métodos geofísicos (elétricos) na identificação de uma ou mais zonas mineralizadas em um garimpo desativado.
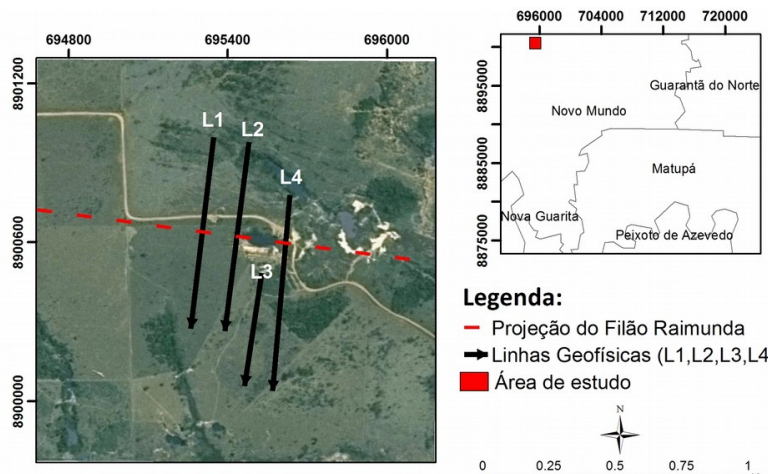

\section{Legenda:}

- Projeção do Filão Raimunda $\rightarrow$ Linhas Geofísicas $(\mathrm{L} 1, \mathrm{~L} 2, \mathrm{~L} 3, \mathrm{~L} 4)$ $\square$ Área de estudo

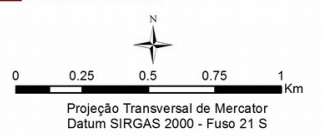

Figure 1: Mapa de localização

\section{Métodos}

A principal aplicação do método de Polarização Induzida (Induced Polarization - IP) ocorre na prospecção de minérios metálicos disseminados e na exploração de águas subterrâneas e geotermais. As medições de polarização induzida são feitas utilizando a mesma configuração dos eletrodos na resistividade convencional, ou seja, com dois 
eletrodos de correntes $(A B)$ e dois eletrodos de potencial (MN) não polarizáveis (Reynolds, 1997).

Os fenômenos que causam a polarização induzida e seus mecanismos eletroquímicos nas rochas e solos incluem a difusão dos íons próximos a minerais metálicos e a mobilidade de íons em soluções presentes nos poros das rochas (Sumner, 1976). Quando a corrente elétrica injetada no solo é interrompida, a corrente entre dois eletrodos não decai instantaneamente para zero milivolt/V. Desta forma, observa-se que o material do subsolo atua como um capacitor, armazenando carga elétrica e tornando-se eletricamente polarizado (Parasnis, 1966; Sumner, 1976; Reynolds, 1997; Keary et al., 2009).

Há dois mecanismos principais causadores de polarização induzida e ambos encontram-se associados aos processos eletroquímicos como o da polarização de membrana e o da polarização de eletrodo.

A medida do efeito do IP no domínio do tempo é dada pela razão $\Delta V / V$ (milivolt/volt), onde $\boldsymbol{V}$ é a voltagem medida enquanto a corrente é propagada; $\Delta V$ é a voltagem remanescente medida em um tempo $t$ após o a interrupção da corrente elétrica (sobretensão). A integração dos valores da razão $\Delta V / V$ com relação à $t$ fornece a área $A$ sobre a curva de decaimento do potencial.

$$
M_{a}=\frac{1}{V} \int_{t_{0}}^{t_{1}} \Delta V \cdot t \quad d t=\frac{A}{V}
$$

Quando é medida a cargabilidade aparente, em verdade, ela é representada por uma média de todas as cargabilidades mensuradas. A cargabilidade verdadeira é tecnicamente impossível de ser obtida no campo, pois cada camada em subsuperfície possui seu valor. Entretanto, tanto a cargabilidade quanto a resistividade real podem ser estimadas por métodos de inversão de dados geofísicos.

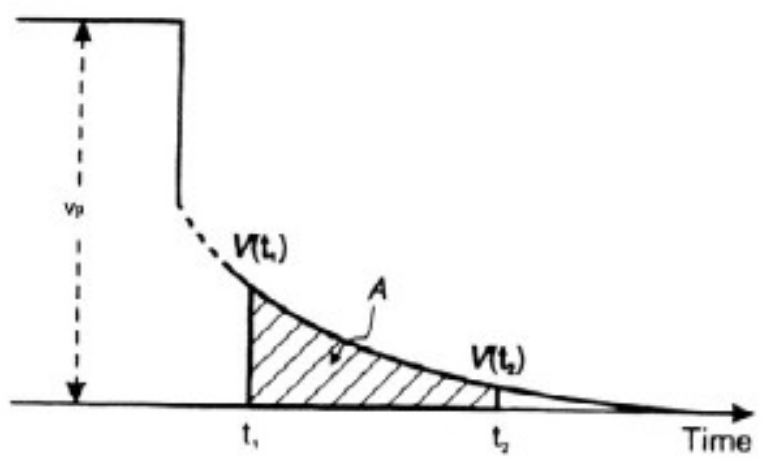

Figure 2: A tensão de decaimento integrada usado como uma medida de cargabilidade $m$ (REYNOLDS, 1997)

No registro dos dados elétricos em campo usaram-se o transmissor VIP 3000 e o receptor ELREC-PRO (IRIS instruments) acompanhado dos seus acessórios.

No campo foram adquiridos quatro seções geoelétricas paralelas equidistantes em aproximadamente 110 metros. As seções tiveram o comprimento planejado de 700 metros, a linha 3 teve de ser redimensionada em decorrência da inundação da cava. A disposição das seções no terreno ocorreu de forma a cruzar perpendicularmente a projeção do filão mineralizado do Garimpo da Raimunda

Para as aquisições dos dados foi utilizado o arranjo dipolodipolo. Em decorrência da melhor resolução horizontal e vertical, o espaçamento usado entre os eletrodos foi de 20 metros. A escolha do espaçamento citado acima ocorreu em função dos registros dos garimpeiros, que evidenciaram a zona mineralizada na profundidade entre 20 e 30 metros. Nesse sentido, para alcançar tal profundidade e conseguir uma boa margem de confiança para a obtenção dos dados foi escolhido um espaçamento maior havendo a consciência 
Costa, A. S. J., Seimetz, E. X., Canata, R. E.

por parte dos pesquisadores de que a resolução poderia ser prejudicada.

O receptor foi configurado para realizar leituras de resistividade e cargabilidade simultaneamente em um tempo de injeção de corrente elétrica de 02 segundos para as janelas temporais de Cole-Cole e para que o receptor fizesse uma média de, no mínimo 03 e de no máximo 5 leituras a fim de obter eventuais leituras anômalas, que poderiam conduzir a erros interpretativos.

\section{Resultados}

Observando o perfil L1 de resistividade (Figura 3a) verificase que a linha está segmentada em três diferentes camadas geoelétricas. A primeira camada se inicia na superfície e tem espessura de até $20 \mathrm{~m}$ com valores de resistividade que variam muito partindo de um valor mínimo de 200 ohm.m até valores de 5000 ohm.m. Nessa camada, os valores de resistividade não tem continuidade lateral. A segunda camada tem espessura entre 15 e $30 \mathrm{~m}$ e valores de resistividade baixo que variam de 10 a 500 ohm.m. Nessa segunda camada existe continuidade lateral e, a primeira metade da seção, alcança o máximo de profundidade e permanece neste nível por 150 metros. A terceira camada tem espessura de 10 a $25 \mathrm{~m}$ e valores de resistividade que variam entre 500 e 5000 ohm.m. Essa última camada aparenta possuir continuidade lateral e contém os maiores valores de resistividade.

A seção de cargabilidade da linha 1 (Figura 3b) apresenta duas camadas. A primeira com espessura variando de 15 a $25 \mathrm{~m}$ ao longo do perfil e valores de cargabilidade variando entre 16 e $60 \mathrm{mV} / \mathrm{V}$. Os valores de cargabilidade dessa camada aparentam estar agrupados em três partes e dentro de cada uma delas não existe continuidade dos valores. A segunda camada com espessura variando de 35 a $45 \mathrm{~m}$ ao longo do perfil e valores de cargabilidade variando entre $4 \mathrm{e}$ $12 \mathrm{mV} / \mathrm{V}$. Essa segunda camada apresenta uma descontinuidade dos valores na primeira metade da seção.

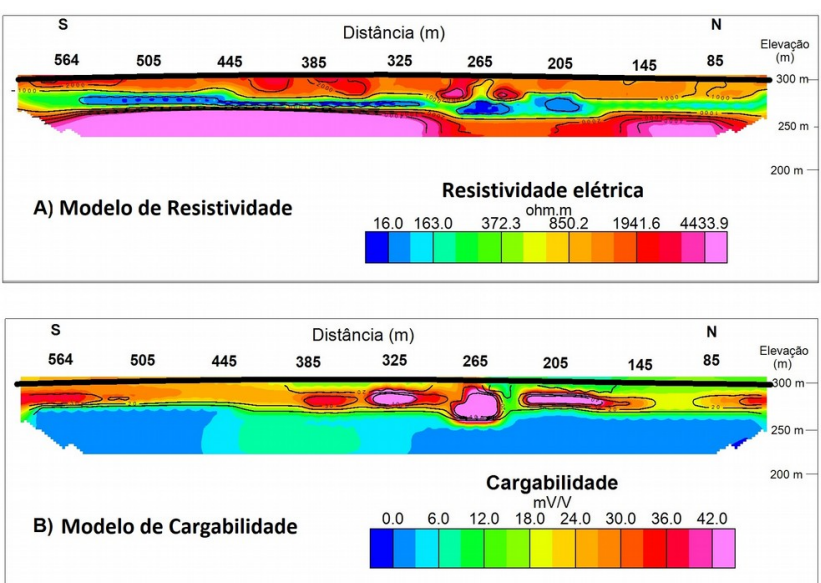

Figure 3: Seção L1, modelo geofísico.

O modelo de sondagem e de resistividade (Figura 4a) apresenta duas camadas. A primeira camada com espessura variando de 25 a $40 \mathrm{~m}$ ao longo do perfil é interpretada como saprólito. A segunda camada com espessura variando de 20 a $30 \mathrm{~m}$ ao longo do perfil é interpretada como o granito. $\mathrm{O}$ modelo resistividade $\mathrm{e}$ cargabilidade (Figura 4b) apresenta três camadas e a presença de uma possível zona mineralizada. A primeira camada com espessura variando de 10 a $20 \mathrm{~m}$ ao longo do perfil é interpretada como solo. A segunda camada com espessura variando de 15 a $25 \mathrm{~m}$ ao longo do perfil é interpretada como saprólito. A terceira camada com espessura variando de 25 a $35 \mathrm{~m}$ ao longo do perfil é interpretada como granito. Próximo a posição 265 m, na profundidade de aproximadamente $20 \mathrm{~m}$, foi constatada uma cargabilidade anômala que foi interpretada como sendo uma zona mineralizada. 


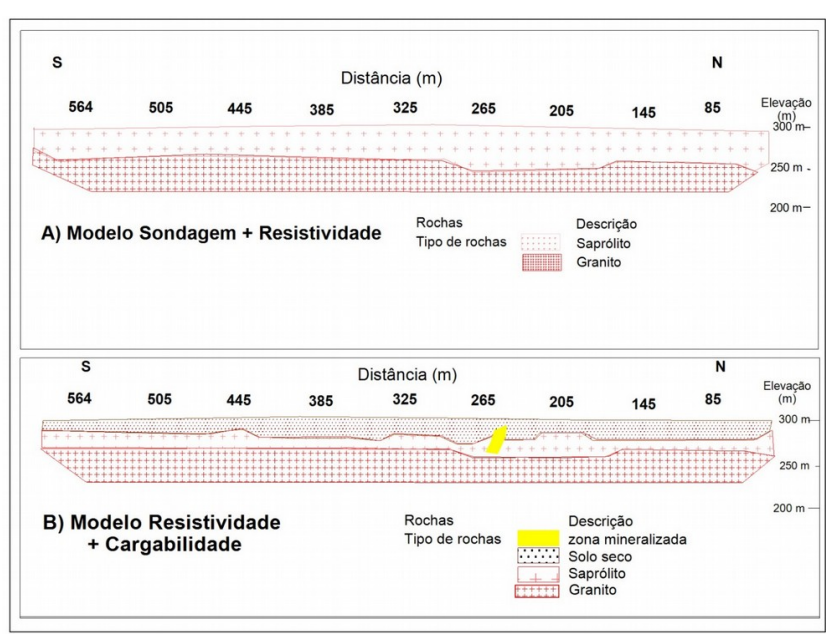

Figure 4: Seção L1, modelo interpretado.

\section{Conclusão}

A aquisição de dados geoelétricos (usando caminhamento elétrico) com o arranjo Dipolo-dipolo no garimpo da

Raimunda, que está inserido na Província Aurífera de Alta Floresta (PAAF), adquirindo dados de cargabilidade e resistividade, utilizando o ELREC PRO (IRIS Instrumento), permitiu diferenciar as estruturas litológicas presentes na área e inferir uma área mineralizada.

Essa aquisição possibilitou a geração de modelos e mapas (de resistividade e cargabilidade). A análise e interpretação feita através destes diferentes resultados da inversão dos dados e usando uma sondagem mecânica para validar as conclusões possibilitou a geração de um modelo litológico sólido. Com isso, nessa área os modelos revelaram conter uma camada de solo (até 15 metros de profundidade), uma camada contendo o saprólito que se revelou um local que contém alta cargabilidade e foi a grande surpresa da pesquisa por conter uma região de alta cargabilidade e baixa resistividade sugerindo a existência de mineralização sulfetada que não foi oxidada. E uma terceira camada que contém o granito no qual não foi observado nenhum valor anômalo de cargabilidade que por consequência não estava mineralizado ou que a amostragem realizada não possibilitou a sua descoberta.

A anomalia detectada na linha 1 está no mesmo alinhamento da mineralização que estava sendo explorada pelos garimpeiros e com uma profundidade mais rasa, o que sugere que a mineralização está indo para a superfície ou a existência de um novo corpo mineralizado.

Para a área do garimpo da Raimunda os resultados obtidos com o método elétrico tiveram ótima correlação com as possíveis estruturas geológicas, o que torna o método uma excelente ferramenta para prospecção mineral para a região.

\section{Agradecimentos}

Agradecimentos à Companhia Matogrossense de Mineração pelo apoio logístico e a Cooperativa de Garimpeiros do Vale do Rio Peixoto de Azevedo pelo apoio financeiro e operacional nas etapas de campo. A Secretaria de Estado de Educação do Distrito Federal - SEEDF pelo suporte financeiro ao autor durante a realização do trabalho. Ao Programa de Pós-Graduação em Geologia e aos Laboratórios de Geofísica Aplicada da Universidade de Brasília (UnB) e ao Laboratório de Geofísica Aplicada da Universidade Federal do Paraná.(UFPR).

\section{Referencias}

BARROS, A. J. P. DE (UNICAMP). Granitos Da Região De Peixoto De Azevedo - Novo Mundo E Mineralizações Auríferas Relacionadas - Província Aurífera Alta Floresta (Mt). [s.I.] Universidade Estadual de Campinas, 2007.

Parasnis, D.S.,1966 Mining Geophysics. Amsterdam: Elsevier.

Reynolds, J.M., 1997. An Introduction to Applied and Environmental Geophysics. John Wiley e Sons Ltd, Baffins Lane, Chichester,England, 796p.

Sumner, J.S., 1976. Principle of Induced Polarization for Geophysical Exploration. Amsterdam: Elsevier. 277p. 
Costa, A. S. J., Seimetz, E. X., Canata, R. E.

KEAREY, P.; BROOKS, M.; HILL, I., 2009. Geofísica de exploração. Tradução Maria Cristina Moreira Coelho. São

Paulo: Oficina do Texto, 438p 